\title{
EFFECTS OF EMPLOYEES ATTITUDE TO WORK ON PRODUCTIVITY
}

\author{
Dr .C K GOMATHY, Ms. NIVEDITHA.Y, MS ASWINI .Y, MS. VANDHANA .T \\ Sri Chandrasekharendra Saraswathi Viswa Mahavidyalaya, Kanchipuram
}

\begin{abstract}
Workplace attitude will have an impact on the presence of innovation and creativity, which can lead to a gradual increase in the productivity of an organization. Workers with a positive attitude toward their job and the company are more likely to make helpful suggestions and they make the ideas that help in the growth of the business. On the other hand, workers with a negative attitude may only be concerned with producing enough to get by while having little interest in innovation and they are least bothered about the improvement of the company. Companies that experience high employee turnover levels not only incur the high costs associated with hiring workers, they also experience reduced productivity until the new workers are up to speed. Employees who feel good about their jobs and workplace may be less likely to leave for greener pastures, helping companies to minimize the productivity gap associated with turnover. Employees with negative attitudes may eventually seek an improved work situation, decide to leave the company.
\end{abstract}

Keywords: Work place, Organizations, Job satisfaction, Co-Workers, Client Interaction

\section{I.INTRODUCTION}

More manpower is needed for an effective and productive organization to be happy and fine with their job profiles so they can put their entire efforts into the growth of an organization. Employee attitude can have more impact on organizations like the performance of both employees and the organization should understand each other. The term Attitude can be defined as the psychological state of mind or mental state of the employee.

When it comes to the workplace, employees can have either a positive or negative attitude about specific work tasks, management, etc. If the employee with a positive attitude helps to increase the growth of a company whereas an employee with a bad attitude results in apathy to daily tasks. Productivity refers to the efficiency of the production of goods or services expressed by some measure. Attitude and productivity are more likely to be positive when employees are happy and engaged. There are some factors on employees' attitude mainly job satisfaction, commitment, job involvement. This study is an attempt to know what kind of employees engaged in good service performance and at the same time to know about the factors that affect the employee's performance.

In the current highly uncertain and competitive business environment, positive attitudes can become a fundamental stone for competitive advantage and success. So, we aimed to assess the most important factors of work-related attitude that influence the performances of employees. It is now a common phenomenon in many organizations to see some workers sleeping on their tables in the office or indulging in gossip outside their office when there is cheap work left in the office left to be done. There is a common saying among workers that "governments work is not anybody work". This attitude to work is common in most of the federal government and it is very bad.

The perspectives of representatives in the work environment can significantly affect the business all in all. Attitude is one of the covered-up, difficult to-gauge factors that turn out to be critical to the

\begin{tabular}{llll}
\hline \hline C 2022, IJSREM & | www.ijsrem.com & DOI: 10.55041/IJSREM11677 & Page 1
\end{tabular}


accomplishment of an organization. Regardless of whether for better or for more regrettable, representative perspectives will more often than not radically affect the efficiency of a business, both straightforwardly and through the impact on other occupation-related elements.

\section{II.PROBLEM STATEMENT}

The responsibility of employers to their work has radically declined as of late contrasted with their disposition to work years prior. This time individuals would not work for their compensation, all things being equal, they work independently leisurely so as not to complete this work on schedule with an end goal to do additional time and get more compensation. In any event, when they work it is constantly finished with less worry, without disapproving with regards to the nature of their result and the productivity of the business concerned, a portion of these workers go to the extent that gathering wages and pay rates from organizations where they didn't work which means harvesting where one didn't plant. The present circumstance is the thing is been alluded to as "phantom employee" this mentality of employee is with the end goal that they have set up collaboration targets the specialists go similarly as concerning and limiting individuals matter wrongfully trying to gather cash from the impacted customers unto their own pocket rather than the organizations. A few specialists settle organization gear independently trying to get more cash flow. Some of them issue fashion power bills to their clients to gather the cash when instalment is made. Likewise, endeavours would be made to track down a solution for this disposition of labourers to their singular work.

The mentalities of representatives in the working environment can significantly affect the business overall. Disposition is one of the covered-up, difficult to-gauge factors that turn out to be significant to the accomplishment of an organization. Regardless of whether for better or for more awful, representative perspectives will quite often definitely affect the efficiency of a business, both straightforwardly and through the impact on other occupation-related variables.

\section{III.WORK ENVIRONMENT}

Workplace attitudes, both positive and negative, are infectious and can easily spread to co-workers. Negative employee attitudes can have a ripple effect. Decreased trust and goodwill toward co-workers harms collaboration, decreasing productivity. A negative social environment isolates individual employees and creates incentives to avoid or leave the job. By contrast, positive attitudes make interaction and collaboration more pleasant and productive. The encouraging social atmosphere that results from good attitudes creates incentives to be part of the team and gives employees a sense of belonging and emotional investment with the success of the company.

\section{COMMITMENT \& MAINTENANCE}

The principal factor subject to representative mentalities is commitment. Representatives that have a negative disposition toward their organization are undeniably bound to be withdrawn, satisfying their positions with minimal measure of work conceivable and at the most reduced quality level. This mentality of withdrawal, detachment, and absence of worry for the organization's prosperity is exorbitant to managers 
via lost efficiency. Representatives with similar abilities and expertise levels are probably going to be commonly more useful assuming that they have an inspirational perspective toward work, and feel associated, submitted, and put resources into the achievement of the organization.

In light of their perspectives toward work, representatives feel pretty much dedicated to the gig. Those with a for the most part regrettable viewpoint at their work circumstance have not a great explanation to feel put resources into a future with the organization. They can leave whenever and may very well be sitting tight for the ideal open door. High worker turnover is essentially expensive to business in various ways, including preparing, employing assets, and work left scattered. Paradoxically, workers with uplifting outlooks toward the gig are bound to foster a feeling of obligation to the business and remain for the long stretch, bringing down turnover costs and expanding usefulness through experience, reports "Entrepreneur."

\section{V.CLIENT INTERACTION}

Not all employees interact directly with customers and clients, but when they do, their attitude is a reliable predictor of customer satisfaction. Even the employees who don't have direct contact with clients can influence through their attitudes the level of care and customer service. A negative attitude is likely to manifest in disengagement from customers and lack of concern for their needs. Customers are an annoyance and an inconvenience to employees with a bad attitude. On the other hand, a positive and engaged attitude is likely to result in courtesy, emotional engagement and a real concern for the well-being and satisfaction of the customer.

Organizations with high levels of productivity are able to work more quickly, efficiently and effectively than organizations with low levels of productivity. Working environments that promote high employee productivity will often lead to less waste by more effectively utilizing time, money and resources. By recognizing the traits and characteristics of workplace productivity, companies can develop and implement strategies to increase productivity gains.

\section{CHANGE ADAPTATION \& TEAMWORK}

Workplaces can change as often as possible as organizations update work methodology, present better innovation and add new items and clients. Representatives who show an inspirational perspective toward change might welcome and even hug it, as they might see it as an opportunity to improve their abilities. Subsequently, they might adjust to change more rapidly than a worker with a negative behaviour, diminishing the time it takes to carry out change in a useful way.

A representative's disposition affects the way that she capacities as a feature of a group. For example, as many organizations try hard to make a more assorted work environment, representatives might have to work with individuals of an alternate race, ethnicity, or orientation than they have previously. Representatives who embrace these assorted specialists and will absorb them into their group can cultivate a feeling of collaboration, making the group more useful all the while.

\section{DEVELOPMENT \& TURNOVER}

Working environment mentality can influence the presence of advancement and inventiveness, which can prompt expanded efficiency. Workers with an inspirational perspective toward their work and the organization are bound to make supportive ideas or thoughts that assist the business with developing. 
Then again ,workers with a negative mentality may just be worried about creating to the point of getting by while caring hardly at all about advancement.

Organizations that experience high representative turnover levels not just bring about the significant expenses related to workers, they likewise experience diminished efficiency until the new specialists are up to speed. Representatives who have a decent outlook on their positions and working environment might be less inclined to leave for greener fields, assisting organizations with limiting the usefulness hole related to turnover. Representatives with negative perspectives may ultimately look for a superior work circumstance and choose to leave the organization.

\section{JOB SATISFACTION \& ORGANIZATIONAL COMMITMENT:}

\section{Work Satisfaction and Organizational Commitment}

However the issue might be complicated, it is generally perceived that representatives who have an uplifting outlook are more useful and valuable to the association. One of the essential elements in a worker's attitude is work fulfilment. Assuming representatives partake in their work, feel sure about their capacities to prevail in the undertakings doled out, and like the job they are allocated; they are undeniably bound to have an uplifting outlook in the work environment.

Attention on upgrading position fulfilment will impact an association's needs from the earliest stage in its cooperation with representatives even before they become workers. In particular, the association will be receptive to the worth of a decent worker to work fit. Whenever the association is hoping to enlist somebody to fill a job, it very well may be enticed essentially to employ the most by and large gifted or experienced candidate whether or not that individual's advantages and inclinations match the expected job. A candidate who has incredible information on the business but likes to work in innovative work ought to likely not be recruited for a job in advertising. Likewise, numerous fantastic specialists are not intrigued or agreeable in administration jobs, and setting them in those positions just on the grounds that they dominate as an expert may be an unfortunate decision. Regardless of whether they have the right stuff to succeed, requesting that they acknowledge a job that they are not happy with or that they abhor doesn't give the most noteworthy probability of progress for the organization or the worker himself.

A similar rule of representative to-work fit applies to existing representatives too. Cautious administration practices will watch out for the changing advancements of representative interests. As colleagues fill in their abilities, interests, and aspirations, it is a great approach to give roads that empower those workers to seek after the course that most invigorates them. This will energize their most significant levels of exertion and responsibility, keep their mentalities positive, and consequently make for more prominent efficiency. Here and there this implies permitting representatives to move divisions, or it could basically mean changing their obligations and concentration inside their present job. Obviously, it may not be imaginable $100 \%$ of the time to take special care of each inclination of each representative, and attempting to do as such can turn into a pointless recommendation yet making a true obligation to this guideline is probably going to bring about certain results for the association. 


\section{CONSEQUENCES}

Attitudinal barriers can lead to people with disabilities being patronized by those around them. Some members of a society might believe the disabled can not perform the same tasks as others and that when disabled people meet or exceed expectations they are treated as if their actions are courageous. NCWD believes this can lead to "regulating them to low-skill jobs, setting different job standards (sometimes lower standards which tend to alienate co-workers, sometimes higher standards to prove they cannot handle a job) or expecting a worker with a disability to appreciate the opportunity to work instead of demanding equal pay, equal benefits, equal opportunity and equal access to workplace amenities."

\section{CONCLUSION}

In this competitive era performance of an organization becomes one of the important aspect to service. So, in order to meet the expectation, organization must forecast systematic human resource management. We can deduce from this study that, there is a significant and good relationship between job attitude (job satisfaction, commitment, organizational leadership and job involvement) and job performance in in every sector. In conclusion, the research finding demonstrated that, even though performance of employees and all the four dimensions like, Job attitude, Job involvement, job satisfaction, job leadership and commitment are different but they are closely related and influenced each other.

\section{REFERENCES:}

[1] C.K.Gomathy.(2010),"Cloud Computing: Business Management for Effective Service Oriented Architecture" International Journal of Power Control Signal and Computation (IJPCSC), Volume 1, Issue IV, Oct - Dec 2010, P.No:22-27, ISSN: 0976-268X .

[2] Dr.C K Gomathy, Article: A Study on the recent Advancements in Online Surveying , International Journal of Emerging technologies and Innovative Research ( JETIR) Volume 5 | Issue 11 | ISSN : 2349-5162, P.No:327-331, Nov-2018

[3] Dr.C.K.Gomathy,C K Hemalatha, Article: A Study On Employee Safety And Health Management International Research Journal Of Engineering And Technology (Irjet)- Volume: 08 Issue: 04 | Apr 2021

[4] Dr.C K Gomathy, Article: A Study on the Effect of Digital Literacy and information Management, IAETSD Journal For Advanced Research In Applied Sciences, Volume 7 Issue 3, P.No-51-57, ISSN NO: 2279-543X,Mar/2018

[5] Dr.C K Gomathy, Article: An Effective Innovation Technology In Enhancing Teaching And Learning Of Knowledge Using Ict Methods, International Journal Of Contemporary Research In Computer Science And Technology (Ijcrcst) E-Issn: 2395-5325 Volume3, Issue 4,P.No-10-13, April '2017

[6] Dr.C K Gomathy, Article: Supply chain-Impact of importance and Technology in Software Release Management, International Journal of Scientific Research in Computer Science Engineering and Information Technology ( IJSRCSEIT ) Volume 3 | Issue 6 | ISSN : 2456-3307, P.No:1-4, July-2018. 


\section{AUTHOR DETAILS:}

1.

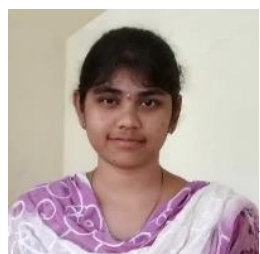

Ms. Yaganti Aswini, BE Computer Science, Sri Chandrasekarendra Saraswathi Viswa Maha Vidyalaya, Sri Jayendra Saraswathi Street, Enathur, Kanchipuram, Tamil Nadu 631561. Her area of intrest is in Human Resources Development and Software Development.

2.

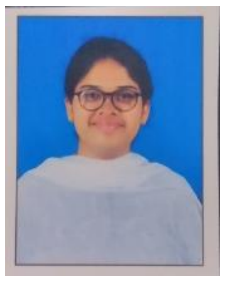

Ms. Yeddula Niveditha, BE Computer Science, Sri Chandrasekarendra Saraswathi Viswa Maha Vidyalaya, Sri Jayendra Saraswathi Street, Enathur, Kanchipuram, Tamil Nadu 631561. Her area of interest is in Software Development, and Machine Learning.

3.

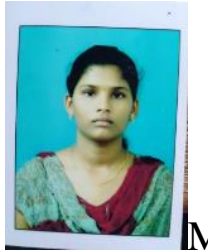

Ms. Thondapu vandhana, BE Computer Science, Sri Chandrasekarendra Saraswathi Viswa Maha Vidyalaya, Sri Jayendra Saraswathi Street, Enathur, Kanchipuram, Tamil Nadu 631561. Her area of interest is in Human Resource and Development.

4.

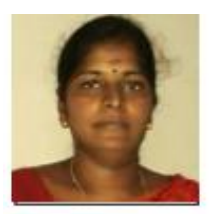

Dr.C.K.Gomathy is Assistant Professor in Computer Science and Engineering at Sri Chandrasekharendra Saraswathi Viswa MahaVidyalaya,Enathur,Kanchipuram,India.Her area of interest in Software Engineering, Web Services, Knowledge Management and IOT. 